\title{
Monoamine Oxidase-A Genetic Variants and Childhood Abuse Predict Impulsiveness in Borderline Personality Disorder
}

\author{
Nathan J. Kolla ${ }^{1,2,3}$, Jeffrey Meyer ${ }^{1,2}$, Marcos Sanches ${ }^{1}$, James Charbonneau ${ }^{3}$ \\ ${ }^{1}$ Centre for Addiction and Mental Health, ${ }^{2}$ Department of Psychiatry, University of Toronto, Toronto, ${ }^{3}$ Department of Psychiatry, University of \\ Western Ontario, London, ON, Canada
}

\begin{abstract}
Objective: Impulsivity is a core feature of borderline personality disorder (BPD) and antisocial personality disorder (ASPD) that likely arises from combined genetic and environmental influences. The interaction of the low activity variant of the monoamine oxidase-A (MAOA-L) gene and early childhood adversity has been shown to predict aggression in clinical and non-clinical populations. Although impulsivity is a risk factor for aggression in BPD and ASPD, little research has investigated potential gene-environment $(G \times E)$ influences impacting its expression in these conditions. Moreover, GXE interactions may differ by diagnosis.

Methods: Full factorial analysis of variance was employed to investigate the influence of monoamine oxidase-A (MAO-A) genotype, childhood abuse, and diagnosis on Barratt Impulsiveness Scale-11 (BIS-11) scores in 61 individuals: 20 subjects with BPD, 18 subjects with ASPD, and 23 healthy controls.

Results: A group Xgenotype Xabuse interaction was present $(A 2,49)=4.4, p=0.018)$, such that the interaction of $M A O A-L$ and childhood abuse predicted greater BIS-11 motor impulsiveness in BPD. Additionally, BPD subjects reported higher BIS-11 attentional impulsiveness versus ASPD participants $(t(1,36)=2.3, p=0.025)$.

Conclusion: These preliminary results suggest that MAOA-L may modulate the impact of childhood abuse on impulsivity in BPD. Results additionally indicate that impulsiveness may be expressed differently in BPD and ASPD.
\end{abstract}

KEY WORDS: Antisocial personality disorder; Borderline personality disorder; Early adverse experiences; Impulsivity; Monoamine oxidase $A$.

\section{INTRODUCTION}

Highly impulsive behavior is central to the phenomenology of both borderline personality disorder (BPD) and antisocial personality disorder (ASPD). Impulsivity is a multi-dimensional neuropsychological construct that in the broadest terms denotes the propensity to engage in maladaptive or problematic behaviors. ${ }^{1)}$ Several subtypes of impulsivity have been described that likely reflect distinct neural processes under genetic control. ${ }^{2,3)}$ Clinically, trait impulsivity has been linked to different forms of aggressive behavior in BPD and ASPD. ${ }^{4-7)}$

\footnotetext{
Received: December 19, 2016 / Revised: March 10, 2017

Accepted: March 30, 2017

Address for correspondence: Nathan J. Kolla, MD, PhD, FRCPC Centre for Addiction and Mental Health Research Imaging Centre, 250 College Street, Room 436, Toronto, ON M5T 1R8, Canada Tel: +416-535-8501, ext. 34248, Fax: +416-979-4656

E-mail: nathan.kolla@mail.utoronto.ca

*This paper was presented at the 55th Meeting of the American College of Neuropsychopharmacology in Hollywood, FL, USA, on December 5, 2016.
}

BPD patients score higher on the Barratt Impulsiveness Scale-11 (BIS-11), ${ }^{8)}$ a self-report measure tapping cognitive, behavioral, and nonplanning aspects of impulsivity, than healthy controls ${ }^{9-11)}$ and other clinically impulsive groups. ${ }^{9,12)}$ Individuals with ASPD similarly endorse higher BIS-11 scores relative to their healthy peers. ${ }^{13,14)}$ Number of ASPD symptoms has additionally been shown to predict BIS-11 motor impulsivity scores in a university sample. ${ }^{15)}$ To the best of our knowledge, only one study has directly compared indices of impulsive behavior in BPD and ASPD. ${ }^{16)}$ All of the subjects in this previous investigation had alcohol dependence and those with comorbid BPD obtained greater total BIS-11 scores than subjects with ASPD.

Evidence suggests that adverse childhood experiences may relate to the impulsivity of BPD and ASPD. In a large, non-clinical sample of young adults, childhood abuse was shown to exert direct effects on both trait disinhibition and borderline features. ${ }^{17)}$ In a cohort of male perpetrators of intimate partner violence, childhood mal-

(a) This is an Open-Access article distributed under the terms of the Creative Commons Attribution Non-Commercial License (http://creativecommons.org/licenses/by-nc/4.0) which permits unrestricted non-commercial use, distribution, and reproduction in any medium, provided the original work is properly cited. 
treatment was associated with manifestation of BPD and ASPD symptoms, which, in turn, predicted greater BIS-11 scores. ${ }^{18)}$ A relationship between impulsive psychopathic traits and childhood sexual abuse has also been reported in a sample of sex offenders, many of whom would meet diagnostic criteria for ASPD. ${ }^{19)}$

Heritable influences may also underlie expression of impulsive BPD/ASPD phenotypes. One genetic marker of interest is monoamine oxidase-A (MAO-A), an X-linked gene whose protein product degrades monoamine neurotransmitters such as serotonin, norepinephrine, and dopamine linked to manifestation of impulsive behavior. ${ }^{20,21)}$ A variable nucleotide tandem repeat (VNTR) polymorphism in the human MAO-A promoter region has been shown to influence transcriptional efficiency in an allelespecific manner depending on the number of copies of the VNTR. High activity MAO-A alleles (MAOA-H), which comprise 3.5 or 4 VNTR copies, are transcribed 2-10 times more efficiently than low activity alleles (MAOA-L), which contain 2, 3, or 5 copies. ${ }^{22)}$ MAO-A allelic variants are associated with $\mathrm{BPD}^{23)}$ and ASPD. ${ }^{24)}$ Impulsive aggression also shows a relation with the low transcription MAO-A allele in healthy samples. ${ }^{25)}$ Therefore, investigating whether MAO-A gene function is related to the impulsivity of ASPD and BPD is a potentially important line of inquiry. Examining how environmental effects moderate genetic risk for impulsivity can provide a more fulsome understanding of how adverse childhood experiences affect the development of impulsive behaviors. A growing body of literature indicates that male and female carriers of MAOA-L who experienced childhood maltreatment exhibit elevated rates of aggression and antisocial behavior, some of which may have been driven by impulsive action. ${ }^{26,27)}$ By contrast, much less is known about whether this gene-environment $(\mathrm{G} \times \mathrm{E})$ combination predisposes to trait impulsiveness. Because trait impulsivity is a powerful risk factor for conduct-disordered behavior and aggression, ${ }^{28)}$ addressing this gap in the literature could refine our knowledge of $\mathrm{G} \times \mathrm{E}$ influences predisposing to violence. One of the first studies to tackle this question found that BIS-11 scores were higher among males with MAOA-H who had reported early childhood abuse. However, a cluster B personality disorder diagnosis was exclusionary in this investigation. ${ }^{29)}$ As far as we are aware, no study has examined these $\mathrm{G} \times \mathrm{E}$ relationships in personality disorder samples. We decided to study BPD and ASPD as separate groups for several reasons. First, there is now clear consensus in the literature that BPD and ASPD are distinct conditions. ${ }^{30)}$ Second, posi- tron emission tomography studies have shown that MAO-A total distribution volume, a measure of MAO-A brain density, is different in BPD versus ASPD. ${ }^{31,32)}$ Third, impulsive behavior in BPD is often associated with self-harming or suicidal behavior and externalized aggression, ${ }^{33)}$ whereas the impulsivity of ASPD mainly involves harm toward others. 7,34$)$

To explore potential $\mathrm{G} \times \mathrm{E}$ relationships in personality disorders, we examined the association of diagnosis, MAO-A genotype, and history of childhood abuse with subtypes of trait impulsiveness. Because the aggression of BPD and ASPD is closely tied to high impulsivity and robust linkages have been described between the MAOA-L allele, childhood abuse, and aggression, we hypothesized that the MAOA-L genetic variant and history of childhood abuse would interact to predict greater trait impulsiveness in BPD and ASPD. We did not make specific predications as to whether certain impulsivity subtypes would differ in the personality disorder groups given the lack of research in this area. As such, we considered our investigation an exploratory analysis.

\section{METHODS}

\section{Participants}

All study components were approved by the Research Ethics Board for Human Subjects at the Centre for Addiction and Mental Health, Toronto, ON, Canada. Each participant provided written consent after study procedures had been explained. A subset of the ASPD and BPD subjects was enrolled in previous neuroimaging studies conducted by our group. ${ }^{31,32)}$ In total, 61 subjects participated in the current study: 18 subjects with ASPD, 20 subjects with BPD, and 23 healthy controls.

\section{Personality Disorder Subjects}

\section{ASPD subjects}

Subjects with ASPD were recruited from the community and federal correctional services halfway houses. ASPD was diagnosed following clinical assessment and use of the Structured Clinical Interview for DSM-IV Axis II Disorders (SCID-II) ${ }^{35)}$ by a forensic psychiatrist (NJK), who also administered the Structured Clinical Interview for DSM-IV Axis I Disorders (SCID-I). ${ }^{36)}$ To rule out confounds of major mood or psychotic disorders, exclusion criteria included a history of depression, mania, hypomania, or psychotic illness. Current substance abuse or dependence (except alcohol) and comorbid BPD were also exclusionary. 
BPD subjects

BPD participants were recruited from the community, inpatient psychiatric wards, and the dialectical behavior therapy clinic at our institution. BPD subjects were clinically assessed by NJK using the SCID-I and SCID-II. Bipolar disorder, psychotic illness, comorbid ASPD, and current substance abuse or dependence were designated as exclusion criteria.

\section{Control Subjects}

Healthy controls were recruited from the community and were clinically assessed by NJK with the SCID-I and SCID-II. Healthy controls had no history of psychiatric illness.

\section{Additional Study Criteria}

All study participants were medication free, non-smoking, and provided negative urine toxicology tests for illicit substances.

\section{Measures}

Impulsivity measures

\section{Barratt Impulsiveness Scale-11 (B/S-11)}

The BIS-11 is self-report instrument indexing an impulsivity construct that consists of three subscales: motor impulsiveness, attentional impulsiveness, and non-planning impulsiveness. BIS-11 total score shows good internal consistency in healthy and psychiatric samples. ${ }^{8)}$ Whereas the motor impulsiveness subscale indexes acting without thinking and a lack of perseverance, the attentional impulsiveness subscale reflects cognitive disturbance and the inability to remain focused on an immediate task, and the nonplanning impulsiveness subscale captures lack of self-control. ${ }^{37)}$ BIS-11 impulsivity data for a subset of the BPD and ASPD participants have been reported previously. ${ }^{31,32)}$

\section{Childhood Trauma Questionnaire Short Form (CTQ-SF)}

The CTQ-SF is a self-report measure that retrospectively assesses several categories of childhood abuse and neglect. ${ }^{38)}$ The CTQ-SF demonstrates good construct validity for assessing childhood maltreatment across clinical and non-clinical samples. Cronbach alpha scores for the sexual and physical scales exceed 0.90 , indicative of excellent internal consistency. ${ }^{39)}$ The 10 items indexing physical abuse and sexual abuse factor scores (five items each) were measured in the current study. Items follow a
Likert-type response style from 1 to 5 and are organized to reflect the frequency of abusive experiences (never true, rarely true, sometimes true, often true, very often true). History of childhood abuse was designated by a positive endorsement of any of the physical abuse or sexual abuse items.

\section{Psychopathy Checklist-Revised (PCL-R)}

The PCL- ${ }^{40)}$ is a clinician-rated instrument that assesses interpersonal and behavioral features of psychopathy. The PCL-R includes 20 items that are rated from 0 to 2 based on whether the trait is present $(0=$ no; $1=$ maybe; $2=y e s)$. Official criminal records in combination with a clinical assessment were used to score the PCL-R. PCL-R data were available for the ASPD and healthy participants.

\section{Genetics}

The MAO-A VNTR locus was amplified using standard PCR procedures with primers as previously described. ${ }^{41)}$ Minor changes were implemented, including labeling the forward primer with 5 ' HEX modifier, to allow for electrophoresis and visualization on a capillary sequencer. Briefly, $125 \mathrm{ng}$ total genomic DNA was combined with $1 \times \mathrm{PCR}_{\mathrm{x}}$ amplification buffer, $1.5 \mathrm{mM} \mathrm{MgSO}_{4}$, and $1 \times \mathrm{PCR}_{\mathrm{x}}$ enhancer solution that accompanied the Invitrogen ${ }^{\mathrm{TM}} \mathrm{PCR}_{\mathrm{x}}$ Enhancer Kit (ThermoFisher Scientific, Waltham, MA, USA), along with $0.2 \mathrm{mM}$ of each $\mathrm{dNTP}, 0.0975 \mu \mathrm{g}$ of each primer, and $0.5 \mathrm{U}$ Taq polymerase in a total reaction volume of $20 \mu \mathrm{L}$. Cycling conditions were as previously described ${ }^{41)}$ with an additional denaturation step of 5 minutes at $95^{\circ} \mathrm{C}$. One microlitre of the amplified product was electrophoresed and visualized using the ABI 3130 Genetic Analyzer system and GeneMapper software (ThermoFisher Scientific). Because the MAO-A gene is located on the $\mathrm{X}$ chromosome, males are hemizygous and females are heterozygous or homozygous at this locus. Individuals with 2, 3, or 5 copies of the MAO-A VNTR were classified as MAOA-L carriers, while those with 3.5 or 4 copies were classified as MAOA-H carriers. Female heterozygotes were categorized as MAOA-L carriers, consistent with previous research. ${ }^{42}$

\section{Statistical Analysis}

Full factorial analysis of variance (ANOVA) was specified to investigate $\mathrm{G} \times \mathrm{E}$ interactions contributing to impulsivity subtypes. Predictor variables included diagnostic group, MAO-A genotype, and childhood abuse. Dependent variables included BIS-11 motor, nonplanning, and attentional subscale scores. Separate models were cre- 
ated for each dependent variable given the high degree of correlation among outcome variables. Post-hoc tests were conducted using independent samples $t$ tests. Group comparisons of demographic, clinical, and impulsivity data were achieved using chi square tests, independent samples $t$ tests, and Mann-Whitney $U$ tests. Pearson correlations tested the relationship between impulsivity measures. The $p$ values less than 0.05 were considered significant for each test. For the statistic analyses, IBM SPSS Statistics for Windows, version 24.0 (IBM Co., Armonk, NY, USA) was used.

\section{RESULTS}

\section{Clinical and Demographic Data}

As presented in Table 1, groups were similar in age, ancestry, and frequency of the low expression MAO-A

Table 1. Demographic and clinical characteristics

\begin{tabular}{|c|c|c|c|}
\hline Characteristic & $\begin{array}{c}\text { BPD } \\
\text { subjects } \\
(n=20)\end{array}$ & $\begin{array}{c}\text { ASPD } \\
\text { subjects } \\
(n=18)\end{array}$ & $\begin{array}{l}\text { Healthy } \\
\text { controls } \\
(n=23)\end{array}$ \\
\hline Age $(y r)^{a}$ & $33.4 \pm 11.0$ & $36.8 \pm 8.7$ & $34.8 \pm 8.0$ \\
\hline \multicolumn{4}{|l|}{ Ancestry $(\%)^{b}$} \\
\hline Caucasian & 65.0 & 50.0 & 54.2 \\
\hline African Canadian & 10.0 & 25.0 & 4.2 \\
\hline Asian & 15.0 & 15.0 & 29.2 \\
\hline Other & 10.0 & 10.0 & 12.5 \\
\hline Education $(y r)^{a_{*}}$ & $13.9 \pm 2.3$ & $13.8 \pm 2.4$ & $16.0 \pm 1.8$ \\
\hline Childhood abuse (\%) $)^{b * *}$ & 85.0 & 70.0 & 16.7 \\
\hline LOW MAO-A $(\%)^{b}$ & 30.0 & 55.6 & 43.5 \\
\hline$P C L-R^{C \star * \star}$ & & $25.8 \pm 6.1$ & $2.9 \pm 2.5$ \\
\hline
\end{tabular}

Values are presented as mean \pm standard deviation or percent only. $\mathrm{BPD}$, borderline personality disorder; ASPD, antisocial personality disorder; MAO-A, monoamine oxidase-A; PCL-R, Psychopathy Checklist-Revised.

ane-way analysis of variance; ${ }^{b}$ chi-square; ${ }^{a}$ Mann-Whitney $U$ test: ${ }^{*} p=0.001,{ }^{* *} p<0.001,{ }^{* * *} p<0.0001$. allele. An independent samples $t$ test similarly revealed no difference in age between the BPD and ASPD groups: $t(1,36)=1.075, p=0.29$. VNTR allele frequencies for the healthy group were similar to results obtained from other samples. ${ }^{22)}$ Groups showed differences in education level. Post-hoc tests revealed that ASPD participants completed fewer years of education compared with the healthy group $(p=0.005)$. Personality disorder groups did not differ in years of education completed $(p=1.0)$. Groups differed in frequency of self-reported childhood abuse. Abuse was more common in BPD and ASPD subjects compared with healthy controls (BPD vs. health: $\chi^{2}(1)=27.8, p<0.001$; ASPD vs. health: $\left.\chi^{2}(1)=14.7, p<0.001\right)$. BPD and ASPD groups did not differ in frequency of childhood abuse $\left(\chi^{2}(1)=0.16, p=0.18\right)$.

\section{Correlations between Impulsivity Measures}

Scores for each BIS-11 subscale were highly and significantly correlated with each other in the total sample ( $r=0.67$ to 0.71 ; all $p$ values $<0.001)$.

\section{Models Testing GXE Interactions on Impulsivity Measures}

\section{BIS-11 motor impulsiveness}

A three-way ANOVA yielded an effect of group on BIS-11 motor impulsiveness (Table 2). Motor impulsiveness scores were higher in the BPD (mean=29.7, standard deviation $[\mathrm{SD}]=6.7)$ and $\mathrm{ASPD}($ mean=30.2, $\mathrm{SD}=5.1)$ groups compared with the healthy group (mean=21.0, $\mathrm{SD}=6.7$; BPD vs. health: $t(1,41)=3.7, p<0.001$; ASPD vs. health: $t(1,39)=4.3, p<0.001)$. No difference in motor impulsiveness scores emerged between ASPD and BPD groups $(t(1,36)=0.25, p=0.80)$. A group $\times$ genotype $\times$ abuse

Table 2. Dependent variable: Barratt motor impulsiveness

\begin{tabular}{|c|c|c|c|c|c|}
\hline Source & Type III sum of squares & $d f$ & Mean square & $\mathrm{F}$ & Sig. \\
\hline Corrected model & $1,116.660^{*}$ & 11 & 101.515 & 4.920 & 0.000 \\
\hline Intercept & $23,534.901$ & 1 & $23,534.901$ & $1,140.615$ & 0.000 \\
\hline Groups & 460.851 & 2 & 230.425 & 11.168 & 0.000 \\
\hline Abuse & 0.002 & 1 & 0.002 & 0.000 & 0.992 \\
\hline MAO-A & 16.581 & 1 & 16.581 & 0.804 & 0.374 \\
\hline Groups×abuse & 6.482 & 2 & 3.241 & 0.157 & 0.855 \\
\hline Groups $\times$ MAO-A & 106.194 & 2 & 53.097 & 2.573 & 0.087 \\
\hline Abuse $\times$ MAO-A & 15.870 & 1 & 15.870 & 0.769 & 0.385 \\
\hline Groups $\times$ abuse $\times M A O-A$ & 180.225 & 2 & 90.113 & 4.367 & 0.018 \\
\hline Error & $1,011.042$ & 49 & 20.634 & & \\
\hline Total & $44,283.980$ & 61 & & & \\
\hline Corrected total & $2,127.702$ & 60 & & & \\
\hline
\end{tabular}

MAO-A, monoamine oxidase-A; df, degrees of freedom; Sig., significance.

${ }^{*} R$ squared $=0.525$ (adjusted $R$ squared $=0.418$ ). 


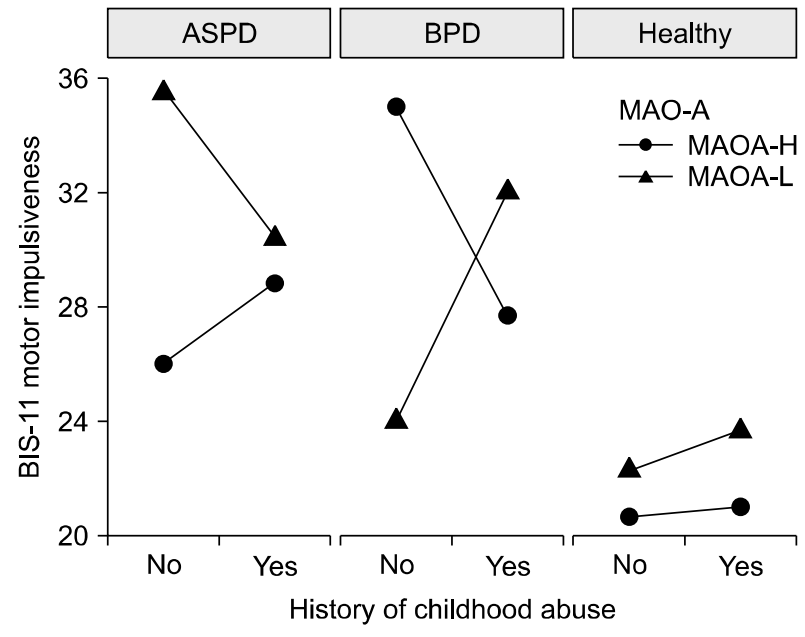

Fig. 1. Three-way interaction indicating that in the bordeline personality disorder (BPD), the combination of the MAOA-L genotype and history of childhood abuse was associated with greater BIS-11 motor impulsiveness scores.

ASPD, antisocial personality disorder; MAO-A, monoamine oxidase-A; MAOA-H, high activity MAO-A alleles; MAOA-L, Iow activity MAO-A alleles; BIS-II, Barratt Impulsiveness Scall-II. interaction emerged from the model $(F(2,49)=4.4$, $p=0.018$ ) (Fig. 1). Among BPD subjects, the interaction of MAOA-L genotype and history of childhood abuse predicted BIS-11 motor impulsiveness scores. In the ASPD subsample, motor impulsiveness did not differ according to abuse history for either genotype (MAOA-L/abuse: mean $=30.4, \mathrm{SD}=4.0$ vs. MAOA-L/no abuse: mean $=35.5$, $\mathrm{SD}=3.5 ; t(1,8)=1.4, p=0.16$; MAOA-H/ abuse: mean $=28.8$, $\mathrm{SD}=4.0$ vs. $\mathrm{MAOA}-\mathrm{H} /$ no abuse: mean $=26.0, \mathrm{SD}=1.7$; $t(1,8)=-0.8, p=0.40)$. Similarly, in the healthy sample, motor impulsiveness scores did not depend on childhood abuse for either genotype (MAOA-L/abuse: mean $=23.7$, $\mathrm{SD}=0.6$ vs. $\mathrm{MAOA}-\mathrm{L} / \mathrm{no}$ abuse: mean $=22.3, \mathrm{SD}=6.3$; $t(1,8)=-0.4, \quad p=0.66$; MAOA-H/abuse: mean $=21.0$, $\mathrm{SD}=20.8$ vs. $\mathrm{MAOA}-\mathrm{H} /$ no abuse: mean $=20.7, \mathrm{SD}=3.4$; $t(1,11)=-0.07, p=0.94)$.

\section{BIS-11 attentional impulsiveness}

An effect of group was observed for BIS-11 attentional impulsiveness scores (Table 3). BPD (mean=23.4,

Table 3. Dependent variable: Barratt attentional impulsiveness

\begin{tabular}{|c|c|c|c|c|c|}
\hline Source & Type III sum of squares & $d f$ & Mean square & $\mathrm{F}$ & Sig. \\
\hline Corrected model & $968.449^{*}$ & 11 & 88.041 & 4.830 & 0.000 \\
\hline Intercept & $11,572.015$ & 1 & $11,572.015$ & 634.838 & 0.000 \\
\hline Groups & 329.105 & 2 & 164.552 & 9.027 & 0.000 \\
\hline Abuse & 0.653 & 1 & 0.653 & 0.36 & 0.851 \\
\hline MAO-A & 92.972 & 1 & 92.972 & 5.100 & 0.028 \\
\hline Groups $\times$ abuse & 6.716 & 2 & 3.358 & 0.184 & 0.832 \\
\hline Groups×MAO-A & 51.295 & 2 & 25.648 & 1.407 & 0.255 \\
\hline Abuse $\times M A O-A$ & 10.669 & 1 & 10.669 & 0.585 & 0.448 \\
\hline Groups×abuse $\times M A O-A$ & 47.970 & 2 & 23.985 & 1.316 & 0.278 \\
\hline Error & 893.186 & 49 & 18.228 & & \\
\hline Total & $22,489.883$ & 61 & & & \\
\hline Corrected total & $1,861.636$ & 60 & & & \\
\hline
\end{tabular}

MAO-A, monoamine oxidase-A; df, degrees of freedom; Sig., significance.

${ }^{*} R$ squared $=0.520$ (adjusted $R$ squared $=0.413$ ).

Table 4. Dependent variable: Barratt nonplanning impulsiveness

\begin{tabular}{|c|c|c|c|c|c|}
\hline Source & Type III sum of squares & $d f$ & Mean square & $\mathrm{F}$ & Sig. \\
\hline Corrected model & $1,750.635^{\star}$ & 11 & 159.149 & 5.063 & 0.000 \\
\hline Intercept & $24,847.522$ & 1 & $24,847.522$ & 790.407 & 0.000 \\
\hline Groups & 732.905 & 2 & 366.453 & 11.657 & 0.000 \\
\hline Abuse & 0.349 & 1 & 0.349 & 0.011 & 0.916 \\
\hline MAO-A & 15.551 & 1 & 15.551 & 0.495 & 0.485 \\
\hline Groups $\times$ abuse & 33.497 & 2 & 16.748 & 0.533 & 0.590 \\
\hline Groups $\times$ MAO-A & 63.207 & 2 & 31.604 & 1.005 & 0.373 \\
\hline Abuse $\times M A O-A$ & 0.418 & 1 & 0.418 & 0.013 & 0.909 \\
\hline Groups $\times$ abuse $\times$ MAO-A & 72.419 & 2 & 36.209 & 1.152 & 0.324 \\
\hline Error & $1,540.382$ & 49 & 31.436 & & \\
\hline Total & $48,356.000$ & 61 & & & \\
\hline Corrected total & $3,291.016$ & 60 & & & \\
\hline
\end{tabular}

MAO-A, monoamine oxidase-A; df, degrees of freedom; Sig., significance.

${ }^{*} R$ squared $=0.532$ (adjusted $R$ squared $=0.427$ ). 
$\mathrm{SD}=6.3$ ) and ASPD (mean=19.0, $\mathrm{SD}=4.7$ ) groups reported greater attentional impulsiveness than healthy controls (mean $=15.0, \mathrm{SD}=6.4$; BPD vs. health: $t(1,41)=4.3, p$ $<0.001$; ASPD vs. health: $t(1,39)=2.2, p=0.035)$. Among the personality disorder groups, BPD participants reported greater attentional impulsiveness than ASPD subjects: $t(1,36)=2.3, p=0.025$. The three-way interaction effect was not significant.

\section{BIS-11 nonplanning impulsiveness}

There was an effect of group for BIS-11 nonplanning impulsiveness scores (Table 4). BPD (mean $=32.7$, $\mathrm{SD}=8.5$ ) and ASPD (mean=30.1, $\mathrm{SD}=6.4$ ) subjects had higher scores than healthy participants (mean $=21.2$, $\mathrm{SD}=8.6$; BPD vs. health: $t(1,41)=4.4, p<0.001$; ASPD vs. health: $t(1,39)=3.7, p<0.001)$. No difference in scores emerged between ASPD and BPD groups $(t(1,36)=1.1, p=0.30)$, and the three-way interaction effect was not present.

When all analyses were re-run and education level was included as a covariate, results remained unchanged.

\section{DISCUSSION}

As far as we are aware, this investigation is the first to highlight $\mathrm{G} \times \mathrm{E}$ interactions relevant to the expression of impulsivity subtypes in personality disorders characterized by high impulsiveness. Consistent with our main hypothesis, we found that the low expression MAO-A genetic variant in combination with a history of childhood abuse predicted greater motor impulsiveness among the BPD participants. An additional study finding is that BPD subjects reported greater attentional impulsiveness compared with ASPD participants. Overall, our results suggest that MAO-A gene effects may moderate the influence of early adverse experiences on risk for increased impulsivity among individuals with BPD. Differences between ASPD and BPD groups further highlight the notion that these disorders have distinct biological markers. We also propose that the $\mathrm{G} \times \mathrm{E}$ effects on impulsivity detected in the BPD subsample have relevance for understanding previous work linking the MAOA-L allele and childhood abuse to aggression and/or conduct-disordered behavior.

Our principal finding is that a history of childhood maltreatment predisposed to greater motor impulsiveness among MAOA-L but not MAOA-H carriers with BPD. Previous investigations that explored links between childhood abuse and trait impulsivity have not always detected associations, ${ }^{43)}$ possibly because potential $\mathrm{G} \times \mathrm{E}$ inter- actions were not examined. Emotional dysregulation is a cardinal feature of BPD closely tied to trait motor impulsiveness. ${ }^{44)}$ Moreover, greater BIS-11 motor impulsiveness scores in BPD are associated with functional brain changes in regions linked to emotional control. ${ }^{45}$ Interestingly, individuals who score high on the BIS-11 motor impulsiveness subscale require more effort to inhibit emotionally arousing stimuli, as evidenced by greater deflection of frontal event-related potential components. ${ }^{46)}$ MAO-A genetic variation may also influence emotional processing linked to inhibitory control. For example, MAOA-L carriers in one functional magnetic resonance imaging study exhibited dampened activation of prefrontal regulatory brain regions when presented with fearful and angry faces. ${ }^{47)}$ The MAO-A gene promoter region is subject to epigenetic modification, ${ }^{48)}$ and childhood abuse is also associated with genome-wide methylation patterns of gene promoter regions in adult DNA. ${ }^{49}$ Therefore, one interpretation of our findings is that early adverse experiences modulate expression of the low-activity MAO-A allele to influence brain function underpinning motor impulsiveness.

Examining the interplay between risk genes, adverse environmental influences, and manifestation of lower-order personality traits, such as impulsivity, can shed light on $\mathrm{G} \times \mathrm{E}$ mechanisms predisposing to more complex behavioral phenomena in BPD. Although violence in BPD is often conceptualized as self-harming or suicidal behavior, violence directed toward others is a common feature of the disorder. ${ }^{50)}$ Impulsivity increases risk for externalized aggression among individuals with high BPD features. ${ }^{51)}$ Identifying G $\times$ E interactions in BPD that predict unidimensional traits linked to aggression could, therefore, provide additional interpretation to $\mathrm{G} \times \mathrm{E}$ interactions studies that tested broad-based forms of violent behavior as outcome measures.

The lack of an association between MAO-A, childhood adversity, and impulsivity in the ASPD subsample could relate to the high level of comorbid psychopathic traits. The mean PCL-R score for the ASPD group was 25.8, indicative of high psychopathic features. Since psychopathic symptoms, including impulsive antisociality, show high heritability, ${ }^{52)} \mathrm{G} \times \mathrm{E}$ influences may be less relevant to development of impulsive symptoms in ASPD subjects with high psychopathy.

Another main study finding to emerge was that BPD participants reported greater attentional or cognitive impulsiveness compared with ASPD subjects. Attentional impulsiveness is elevated in adults with attention deficit 
hyperactivity disorder (ADHD), ${ }^{53)}$ a neurodevelopmental condition that may exist as a continuum of quantitative traits. ${ }^{54)}$ Although ADHD is frequently comorbid with $\mathrm{BPD}$ and ASPD, ${ }^{55,56}$ it shows stronger links with BPD. ${ }^{57)}$ We did not assess our study participants for ADHD. Yet, attentional impulsiveness is correlated with other measures of ADHD symptom severity. ${ }^{58)}$ Because attentional problems relate to poor functional outcomes in $\mathrm{BPD}^{59)}$ and greater ADHD symptom burden predicts more borderline symptoms, ${ }^{60,61)}$ we suggest that attentional impulsiveness may be of greater relevance to the psychopathology of BPD compared with ASPD. This supposition is bolstered by data presented in one study indicating that the effect size for differences in BIS-11 subscale scores between ASPD and healthy controls was smallest for attentional impulsiveness. ${ }^{13)}$

We acknowledge several limitations of our investigation. First, the smaller group sizes may have limited the ability to detect additional $\mathrm{G} \times \mathrm{E}$ interactions present in a larger cohort. Although one option would have been to combine ASPD and BPD participants into a single group to increase study power, we were interested in exploring differences between the two disorders for the important reasons noted above. We would also add that the stringent exclusion criteria applied to the clinical groups (e.g., no smoking or substance use) increased the difficulty of recruiting participants. However, these restrictions enabled us to study personality disorder phenotypes that were free of major confounds. Second, we focused our analyses on self-report aspects of impulsivity and did not include behavioral measures. We opted for the former method, because examining genetic contributions to impulsiveness was a primary study objective, and trait-based impulsivity measures tend to show high heritability. ${ }^{62-64)}$ Third, the majority of our BPD subjects were female while the ASPD and healthy control groups were all male. Therefore, we cannot overlook the possibility that results were influenced by sex differences.

In summary, we demonstrated that a history of childhood abuse interacts with the low activity MAO-A variant to increase impulsivity in BPD. This result was specific to BPD and adds to a growing literature highlighting the role of $\mathrm{G} \times \mathrm{E}$ effects on the impulsivity of BPD. ${ }^{65,66)}$ Future studies that test the interaction of childhood abuse and MAO-A expression on borderline symptoms closely related to impulsivity could make important inroads to understanding the etiology and development of BPD. In addition, analyzing the effect of MAO-A genotype and history of childhood abuse on the efficacy of novel treat- ments for $\mathrm{BPD}^{67)}$ and impulsivity ${ }^{68)}$ could lead to more targeted interventions for personality disorders.

\section{Acknowledgments}

Funding for this study was provided by an operating grant from the Canadian Institutes of Health Research (CIHR), a CIHR Clinician-Scientist Training Award, an American Psychiatric Association Psychiatric Research Fellowship, and a grant from the Physicians' Services Incorporated Foundation. These organizations had no further role in the study design; in the collection, analysis, and interpretation of data; in the writing of the report; and in the decision to submit the paper for publication.

\section{REFERENCES}

1. de Wit H. Impulsivity as a determinant and consequence of drug use: a review of underlying processes. Addict Biol 2009; 14:22-31.

2. Dalley JW, Everitt BJ, Robbins TW. Impulsivity, compulsivity, and top-down cognitive control. Neuron 2011;69: 680-694.

3. Fineberg NA, Chamberlain SR, Goudriaan AE, Stein DJ, Vanderschuren LJ, Gillan CM, et al. New developments in human neurocognition: clinical, genetic, and brain imaging correlates of impulsivity and compulsivity. CNS Spectr 2014;19:69-89.

4. Brodsky BS, Malone KM, Ellis SP, Dulit RA, Mann JJ. Characteristics of borderline personality disorder associated with suicidal behavior. Am J Psychiatry 1997;154: 1715-1719.

5. Chesin MS, Jeglic EL, Stanley B. Pathways to high-lethality suicide attempts in individuals with borderline personality disorder. Arch Suicide Res 2010;14:342-362.

6. Yen S, Shea MT, Sanislow CA, Grilo CM, Skodol AE, Gunderson JG, et al. Borderline personality disorder criteria associated with prospectively observed suicidal behavior. Am J Psychiatry 2004;161:1296-1298.

7. Blackburn R, Coid JW. Psychopathy and the dimensions of personality disorder in violent offenders. Pers Indiv Differ 1998;25:129-145.

8. Patton JH, Stanford MS, Barratt ES. Factor structure of the Barratt impulsiveness scale. J Clin Psychol 1995;51: 768-774.

9. Berlin HA, Rolls ET, Iversen SD. Borderline personality disorder, impulsivity, and the orbitofrontal cortex. Am J Psychiatry 2005;162:2360-2373.

10. Jacob GA, Gutz L, Bader K, Lieb K, Tüscher O, Stahl C. Impulsivity in borderline personality disorder: impairment in self-report measures, but not behavioral inhibition. Psychopathology 2010;43:180-188.

11. Dougherty DM, Bjork JM, Huckabee HC, Moeller FG, Swann AC. Laboratory measures of aggression and impulsivity in women with borderline personality disorder. Psychiatry Res 1999;85:315-326.

12. Kirkpatrick T, Joyce E, Milton J, Duggan C, Tyrer P, Rogers $\mathrm{RD}$. Altered memory and affective instability in prisoners assessed for dangerous and severe personality disorder. $\mathrm{Br}$ J Psychiatry Suppl 2007;49:s20-s26. 
13. Swann AC, Lijffijt M, Lane SD, Steinberg JL, Moeller FG. Trait impulsivity and response inhibition in antisocial personality disorder. J Psychiatr Res 2009;43:1057-1063.

14. Lijffijt M, Moeller FG, Boutros NN, Burroughs S, Steinberg JL, Lane SD, et al. A pilot study revealing impaired P50 gating in antisocial personality disorder. $J$ Neuropsychiatry Clin Neurosci 2009;21:328-331.

15. Fossati A, Barratt ES, Carretta I, Leonardi B, Grazioli F, Maffei C. Predicting borderline and antisocial personality disorder features in nonclinical subjects using measures of impulsivity and aggressiveness. Psychiatry Res 2004;125: 161-170.

16. Rubio G, Jiménez M, Rodríguez-Jiménez R, Martínez I, Iribarren MM, Jiménez-Arriero MA, et al. Varieties of impulsivity in males with alcohol dependence: the role of Cluster-B personality disorder. Alcohol Clin Exp Res 2007; 31:1826-1832.

17. Trull TJ. Structural relations between borderline personality disorder features and putative etiological correlates. J Abnorm Psychol 2001;110:471-481.

18. Liu N, Zhang Y, Brady HJ, Cao Y, He Y, Zhang Y. Relation between childhood maltreatment and severe intrafamilial male-perpetrated physical violence in Chinese community: the mediating role of borderline and antisocial personality disorder features. Aggress Behav 2012;38:64-76.

19. Graham N, Kimonis ER, Wasserman AL, Kline SM. Associations among childhood abuse and psychopathy facets in male sexual offenders. Personal Disord 2012;3:66-75.

20. Pattij T, Vanderschuren LJ. The neuropharmacology of impulsive behaviour. Trends Pharmacol Sci 2008;29:192199.

21. Lan NC, Heinzmann C, Gal A, Klisak I, Orth U, Lai E, et al. Human monoamine oxidase $A$ and $B$ genes map to $X p$ 11.23 and are deleted in a patient with Norrie disease. Genomics 1989;4:552-559.

22. Sabol SZ, Hu S, Hamer D. A functional polymorphism in the monoamine oxidase A gene promoter. Hum Genet 1998; 103:273-279.

23. Ni X, Sicard T, Bulgin N, Bismil R, Chan K, McMain S, et al. Monoamine oxidase a gene is associated with borderline personality disorder. Psychiatr Genet 2007;17: 153-157.

24. Kolla NJ, Attard S, Craig G, Blackwood N, Hodgins S. Monoamine oxidase A alleles in violent offenders with antisocial personality disorder: high activity associated with proactive aggression. Crim Behav Ment Health 2014;24: 368-372.

25. Manuck SB, Flory JD, Ferrell RE, Mann JJ, Muldoon MF. $A$ regulatory polymorphism of the monoamine oxidase- $A$ gene may be associated with variability in aggression, impulsivity, and central nervous system serotonergic responsivity. Psychiatry Res 2000;95:9-23.

26. Ducci F, Enoch MA, Hodgkinson $\mathrm{C}, \mathrm{Xu} \mathrm{K}$, Catena $\mathrm{M}$, Robin RW, et al. Interaction between a functional MAOA locus and childhood sexual abuse predicts alcoholism and antisocial personality disorder in adult women. Mol Psychiatry 2008; 13:334-347.

27. Byrd AL, Manuck SB. MAOA, childhood maltreatment, and antisocial behavior: meta-analysis of a gene-environment interaction. Biol Psychiatry 2014;75:9-17.

28. Farrington DP. Early predictors of adolescent aggression and adult violence. Violence Vict 1989;4:79-100.

29. Huang YY, Cate SP, Battistuzzi C, Oquendo MA, Brent D, Mann JJ. An association between a functional polymorphism in the monoamine oxidase a gene promoter, impulsive traits and early abuse experiences. Neuropsychopharmacology 2004;29:1498-1505.

30. Paris J, Chenard-Poirier MP, Biskin R. Antisocial and borderline personality disorders revisited. Compr Psychiatry 2013;54:321-325.

31. Kolla NJ, Chiuccariello L, Wilson AA, Houle S, Links P, Bagby RM, et al. Elevated monoamine oxidase-A distribution volume in borderline personality disorder is associated with severity across mood symptoms, suicidality, and cognition. Biol Psychiatry 2016;79:117-126.

32. Kolla NJ, Matthews B, Wilson AA, Houle S, Bagby RM, Links $\mathrm{P}$, et al. Lower monoamine oxidase-A total distribution volume in impulsive and violent male offenders with antisocial personality disorder and high psychopathic traits: an [(11)C] harmine positron emission tomography study. Neuropsychopharmacology 2015;40:2596-2603.

33. Soloff PH, Lis JA, Kelly T, Cornelius J, Ulrich R. Risk factors for suicidal behavior in borderline personality disorder. Am J Psychiatry 1994;151:1316-1323.

34. Tiihonen J, Kuikka JT, Bergström KA, Karhu J, Viinamäki $\mathrm{H}$, Lehtonen J, et al. Single-photon emission tomography imaging of monoamine transporters in impulsive violent behaviour. Eur J Nucl Med 1997;24:1253-1260.

35. First MB, Gibbon M, Spitzer RL, Williams JBW, Benjamin LS. Structured Clinical Interview for DSM-IV Axis II Personality Disorders, (SCID-II). Washington, D.C.:American Psychiatric Press, Inc.;1997.

36. First MB, Spitzer RL, Gibbon M, Williams JBW. Structured Clinical Interview for DSM-IV-TR Axis I Disorders, Research Version, Patient edition (SCID-I/P). New York: Biometrics Research, New York State Psychiatric Institute; 2002.

37. Whiteside SP, Lynam DR. The Five Factor Model and impulsivity: using a structural model of personality to understand impulsivity. Pers Indiv Differ 2001;30:669-689.

38. Bernstein DP, Stein JA, Newcomb MD, Walker E, Pogge $\mathrm{D}$, Ahluvalia T, et al. Development and validation of a brief screening version of the Childhood Trauma Questionnaire. Child Abuse Negl 2003;27:169-190.

39. Thombs BD, Bernstein DP, Lobbestael J, Arntz A. A validation study of the Dutch Childhood Trauma Questionnaire-Short Form: factor structure, reliability, and known-groups validity. Child Abuse Negl 2009;33:518-523.

40. Hare RD. Hare Psychopathy Checklist-Revised. 2nd ed. Toronto:Multi-Health Systems;2003.

41. Deckert J, Catalano M, Syagailo YV, Bosi M, Okladnova $\mathrm{O}$, Di Bella $\mathrm{D}$, et al. Excess of high activity monoamine oxidase A gene promoter alleles in female patients with panic disorder. Hum Mol Genet 1999;8:621-624.

42. Reif A, Weber H, Domschke K, Klauke B, Baumann C, Jacob CP, et al. Meta-analysis argues for a female-specific role of MAOA-uVNTR in panic disorder in four European populations. Am J Med Genet B Neuropsychiatr Genet 2012;159B:786-793.

43. Roy A. Childhood trauma and impulsivity. Possible relevance to suicidal behavior. Arch Suicide Res 2005;9:147-151.

44. Velotti P, Garofalo C, Petrocchi C, Cavallo F, Popolo R, Dimaggio G. Alexithymia, emotion dysregulation, impulsivity and aggression: A multiple mediation model. Psychiatry Res 2016:237:296-303.

45. Hoerst M, Weber-Fahr W, Tunc-Skarka N, Ruf M, Bohus $\mathrm{M}$, Schmahl C, et al. Correlation of glutamate levels in the anterior cingulate cortex with self-reported impulsivity in patients with borderline personality disorder and healthy controls. Arch Gen Psychiatry 2010;67:946-954. 
46. Messerotti Benvenuti S, Sarlo M, Buodo G, Mento G, Palomba D. Influence of impulsiveness on emotional modulation of response inhibition: an ERP study. Clin Neurophysiol 2015;126:1915-1925.

47. Meyer-Lindenberg A, Buckholtz JW, Kolachana B, R Hariri A, Pezawas L, Blasi G, et al. Neural mechanisms of genetic risk for impulsivity and violence in humans. Proc Natl Acad Sci U S A 2006; 103:6269-6274.

48. Shumay E, Logan J, Volkow ND, Fowler JS. Evidence that the methylation state of the monoamine oxidase A (MAOA) gene predicts brain activity of $M A O A$ enzyme in healthy men. Epigenetics 2012;7:1151-1160.

49. Suderman M, Borghol N, Pappas JJ, Pinto Pereira SM, Pembrey M, Hertzman C, et al. Childhood abuse is associated with methylation of multiple loci in adult DNA. BMC Med Genomics 2014;7:13.

50. Coccaro EF, Berman ME, Kavoussi RJ. Assessment of life history of aggression: development and psychometric characteristics. Psychiatry Res 1997;73:147-157.

51. Peters JR, Derefinko KJ, Lynam DR. Negative urgency accounts for the association between borderline personality features and intimate partner violence in young men. J Pers Disord 2017;31:16-25.

52. Blonigen DM, Hicks BM, Krueger RF, Patrick CJ, Iacono WG. Psychopathic personality traits: heritability and genetic overlap with internalizing and externalizing psychopathology. Psychol Med 2005;35:637-648.

53. Malloy-Diniz L, Fuentes D, Leite WB, Correa H, Bechara A. Impulsive behavior in adults with attention deficit/ hyperactivity disorder: characterization of attentional, motor and cognitive impulsiveness. J Int Neuropsychol Soc 2007;13: 693-698.

54. McLoughlin G, Ronald A, Kuntsi J, Asherson P, Plomin R. Genetic support for the dual nature of attention deficit hyperactivity disorder: substantial genetic overlap between the inattentive and hyperactive-impulsive components. $J$ Abnorm Child Psychol 2007;35:999-1008.

55. Matthies SD, Philipsen A. Common ground in attention deficit hyperactivity disorder $(A D H D)$ and borderline personality disorder (BPD)-review of recent findings. Borderline Personal Disord Emot Dysregul 2014;1:3.

56. Storebø OJ, Simonsen E. The association between ADHD and antisocial personality disorder (ASPD): a review. $J$ Atten Disord 2016;20:815-824.

57. Ni HC, Gau SS. Co-occurrence of attention-deficit hyperactivity disorder symptoms with other psychopathology in young adults: parenting style as a moderator. Compr Psychiatry 2015;57:85-96.

58. Dang LC, Samanez-Larkin GR, Young JS, Cowan RL,
Kessler RM, Zald DH. Caudate asymmetry is related to attentional impulsivity and an objective measure of $A D H D$ like attentional problems in healthy adults. Brain Struct Funct 2016;221:277-286.

59. Ruocco AC, Lam J, McMain SF. Subjective cognitive complaints and functional disability in patients with borderline personality disorder and their nonaffected first-degree relatives. Can J Psychiatry 2014,59:335-344.

60. Dalbudak E, Evren C. The impact of childhood traumas, depressive and anxiety symptoms on the relationship between borderline personality features and symptoms of adult attention deficit hyperactivity disorder in Turkish university students. Nord J Psychiatry 2015;69:42-47.

61. Stepp SD, Burke JD, Hipwell AE, Loeber R. Trajectories of attention deficit hyperactivity disorder and oppositional defiant disorder symptoms as precursors of borderline personality disorder symptoms in adolescent girls. J Abnorm Child Psychol 2012;40:7-20.

62. Pedersen NL, Plomin R, McClearn GE, Friberg L. Neuroticism, extraversion, and related traits in adult twins reared apart and reared together. J Pers Soc Psychol 1988;55: 950-957.

63. Hur YM, Bouchard TJ Jr. The genetic correlation between impulsivity and sensation seeking traits. Behav Genet 1997; 27:455-463.

64. Saudino KJ, Gagne JR, Grant J, Ibatoulina A, Marytuina T, Ravich-Scherbo I, et al. Genetic and environmental influences on personality in adult Russian twins. Int J Behav Dev 1999;23:375-389.

65. Wagner S, Baskaya O, Dahmen N, Lieb K, Tadić A. Modulatory role of the brain-derived neurotrophic factor Val66Met polymorphism on the effects of serious life events on impulsive aggression in borderline personality disorder. Genes Brain Behav 2010;9:97-102.

66. Wagner S, Baskaya O, Anicker NJ, Dahmen N, Lieb K, Tadić A. The catechol o-methyltransferase (COMT) val(158)met polymorphism modulates the association of serious life events (SLE) and impulsive aggression in female patients with borderline personality disorder (BPD). Acta Psychiatr Scand 2010;122:110-117.

67. Amamou B, Salah WB, Mhalla A, Benzarti N, Elloumi H, Zaafrane $\mathrm{F}$, et al. Use of clozapine for borderline personality disorder: A case report. Clin Psychopharmacol Neurosci 2016;14:226-228.

68. Spivak B, Shabash E, Sheitman B, Weizman A, Mester R. The effects of clozapine versus haloperidol on measures of impulsive aggression and suicidality in chronic schizophrenia patients: an open, nonrandomized, 6-month study. J Clin Psychiatry 2003;64:755-760. 